\title{
Azithromycin effectiveness against intracellular infections of Francisella
}

\author{
Saira Ahmad', Lyman Hunter², Aiping Qin³, Barbara J Mann³ and Monique L van Hoek*1
}

\begin{abstract}
Background: Macrolide antibiotics are commonly administered for bacterial respiratory illnesses. Azithromycin (Az) is especially noted for extremely high intracellular concentrations achieved within macrophages which is far greater than the serum concentration. Clinical strains of Type B Francisella (F.) tularensis have been reported to be resistant to Az, however our laboratory Francisella strains were found to be sensitive. We hypothesized that different strains/species of Francisella (including Type A) may have different susceptibilities to Az, a widely used and well-tolerated antibiotic.

Results: In vitro susceptibility testing of Az confirmed that F. tularensis subsp. holarctica Live Vaccine Strain (LVS) (Type B) was not sensitive while F. philomiragia, F. novicida, and Type A F. tularensis (NIH B38 and Schu S4 strain) were susceptible. In J774A.1 mouse macrophage cells infected with F. philomiragia, F. novicida, and F. tularensis LVS, $5 \mu \mathrm{g} / \mathrm{ml} \mathrm{Az} \mathrm{applied}$ extracellularly eliminated intracellular Francisella infections. A concentration of $25 \mu \mathrm{g} / \mathrm{ml} \mathrm{Az}$ was required for Francisellainfected A549 human lung epithelial cells, suggesting that macrophages are more effective at concentrating Az than epithelial cells. Mutants of RND efflux components (to/C and ft/C) in F. novicida demonstrated less sensitivity to Az by MIC than the parental strain, but the to/C disc-inhibition assay demonstrated increased sensitivity, indicating a complex role for the outer-membrane transporter. Mutants of acrA and acrB mutants were less sensitive to Az than the parental strain, suggesting that AcrAB is not critical for the efflux of Az in F. novicida. In contrast, F. tularensis Schu S4 mutants $\triangle a c r B$ and $\triangle a c r A$ were more sensitive than the parental strain, indicating that the AcrAB may be important for Az efflux in F. tularensis Schu S4. F. novicida LPS O-antigen mutants ( $w b t N$, wbtE, wbtQ and $w b t A$ ) were found to be less sensitive in vitro to Az compared to the wild-type. Az treatment prolonged the survival of Galleria (G.) mellonella infected with Francisella.

Conclusion: These studies demonstrate that Type A Francisella strains, as well as F. novicida and F. philomiragia, are sensitive to Az in vitro. Francisella LPS and the RND efflux pump may play a role in Az sensitivity. Az also has antimicrobial activity against intracellular Francisella, suggesting that the intracellular concentration of Az is high enough to be effective against multiple strains/species of Francisella, especially in macrophages. Az treatment prolonged survival an in vivo model of Francisella-infection.
\end{abstract}

\section{Background}

Bacteria in the Francisella genus are nonmotile, nonsporulating, gram-negative coccobacilli. Francisella causes a zoonotic disease; humans can become infected via a variety of mechanisms including inhalation of an extremely low infectious dose [1]. F. tularensis primarily targets macrophages where bacterial survival and replication occurs [1]. The genus Francisella is divided into two species: tularensis and philomiragia. Francisella tularensis

* Correspondence: mvanhoek@gmu.edu

1 Department of Molecular and Microbiology, National Center for Biodefense and Infectious Diseases, George Mason University, Manassas, VA, 20120, USA Full list of author information is available at the end of the article has four subspecies: F. tularensis subspecies tularensis (formerly F. tularensis,) F. tularensis subspecies holarctica (which includes the live vaccine strain, LVS), F. tularensis subspecies mediasiatica, and $F$. tularensis subspecies novicida (F. novicida) [2]. Subspecies of Francisella tularensis are further separated into two types depending on their virulence. Type A strains include Francisella tularensis subspecies tularensis Schu S4 (F. tularensis Schu S4) and are more virulent [3], except for the ATCC type strain F. tularensis subsp. tularensis NIH B38 which is avirulent [4-6]. Francisella Type A strains are normally associated with ticks and rabbits and are restricted to North America. Type B strains (Francisella tularensis 
subspecies holarctica and mediasiatica) are less virulent and cause tularemia throughout Eurasia [3].

Standard recommended antibiotic treatment for tularemia includes oral tetracycline antibiotics (e.g. doxycycline) and fluoroquinolones (e.g. ciprofloxacin) which have adverse side-effects on pediatric and the elderly patients, and individuals with liver disease. Aminoglycosides such as streptomycin and gentamicin can be injected intravenously or intramuscularly [7], but are not commonly used. Macrolides are oral antibiotics commonly used to treat bacterial respiratory illnesses. Azithromycin (Az), a member of the azalide subclass of macrolides, binds to the $50 \mathrm{~s}$ subunit of gram-negative bacterial ribosomes, and inhibits translation of mRNA resulting in inhibition of bacterial growth or death [8]. It has been suggested that the two basic amine sites of $\mathrm{Az}$ interact with the negatively charged heptose-phosphate region of lipopolysaccharide (LPS) in order to enter gram-negative bacteria [9]. F. novicida transposon insertion mutants in the genes involved in lipopolysaccharide (LPS) production ( $w b t N, w b t E, w b t Q$ and $w b t A)$ were tested to determine if there might be a role of LPS in Az binding and penetration. Mutations in genes responsible for the synthesis of the $\mathrm{O}$-antigen in $\mathrm{F}$. novicida have been previously shown to decrease virulence and resistance to serum killing while macrophage uptake and replication remained unaffected [10].

A primary mode of bacterial resistance to antibacterial drugs is the expression of drug efflux pumps such as ATP-binding cassette (ABC), the Major Facilitator Superfamily (MFS) transporters, and Resistance-NodulationDivision (RND) efflux system. These inner membrane transport systems are often coupled to the outer membrane TolC system [11]. Francisella novicida has two tolC-like proteins, tolC and the highly related fltC [12]. The ABC Superfamily is thought to be responsible for the export of many different antibiotics. For example, in $E$. coli, macrolides are thought to be transported by the $\mathrm{ABC}$ transporter $\mathrm{MacAB}$ [13]. Although a potential macA gene was identified in F. novicida (FTN_1692), no gene corresponding to $m a c B$ could be identified in the $F$. novicida genome. The RND efflux system consists of a tripartite transporter with an RND pump protein located in the cytoplasmic membrane (AcrB) and a periplasmic membrane fusion protein (AcrA) coupled to the TolC protein in the outer membrane (Figure 1). The RND system can pump many compounds, including macrolides [14]. The AcrAB RND efflux pump was recently demonstrated to be required for $F$. tularensis LVS virulence in mice [15], but not in F. tularensis Schu S4 [16]. The function of the RND efflux system is the removal of harmful substances from inside the cytosol of the bacteria directly to the external medium bypassing the periplasm [15]. Thus we hypothesized that mutants in the RND efflux system

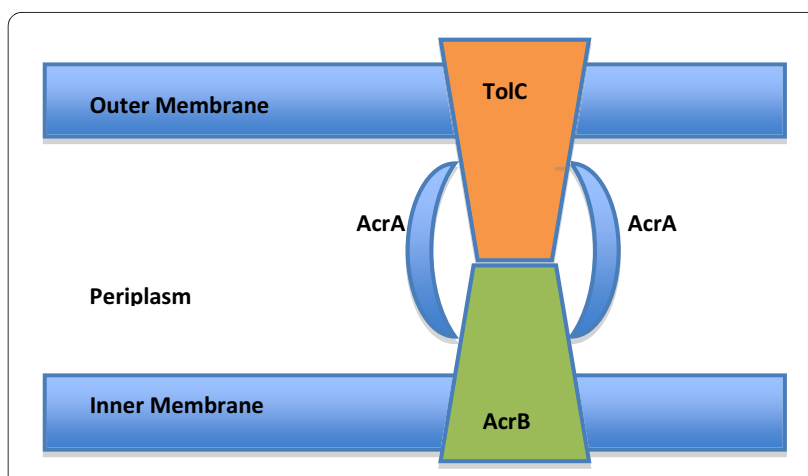

Figure 1 RND efflux pump. A schematic of the RND efflux pump, following [59], to illustrate the relationship between TolC, AcrA and AcrB.

would have altered sensitivity to Az. Transposon insertion mutants of components of the RND efflux system in F. novicida, including tolC, fltC, acrA, and $\operatorname{acr} B$, were tested for their sensitivity to Az. The $d s b B$ gene encodes the cytoplasmic membrane protein that is involved in disulfide bond formation in the periplasm. A $d s b B$ mutant in $F$. novicida was tested because it is transcriptionally linked in an operon with $a c r A$ and $a c r B$ in Francisella. Mutants $\triangle a c r A$ and $\triangle a c r B$ were also tested in the fully virulent strain, F. tularensis Schu S4 [16].

$\mathrm{Az}$, which is commonly prescribed to pediatric patients for treatment of common upper respiratory track and ear infections [17], has low toxicity and few side-effects [18]. When administered, the antibiotic becomes ion-trapped in the acidic lysosomes of white blood cells including macrophages resulting in a high intracellular concentration compared to the plasma during the dose period. Intracellular concentrations remain high after the dose period ends with a half-life of 68 hours [18].

Murine macrophages J774A.1 are a well-studied in vitro model system for tularemia $[19,20]$ and were chosen as a model cell system to study Francisella infection and treatment by Az. The murine macrophage cell line J774A.1 supports the intracellular replication of F. tularensis LVS [19], F. novicida [21], and F. tularensis Schu S4 [16]. For a model of the human system, human lung epithelial cells A549 were chosen. F. tularensis LVS has been previously shown to infect and replicate within A549 cells [22-24]. We hypothesized that the ability of Az to concentrate at high levels within the macrophages may result in effectiveness against intracellular infections by Francisella species, even at extracellular Az levels lower than the MIC.

The larval stage of Galleria (G.)mellonella, wax moth caterpillar, has been used as a model to study infections caused by some bacteria including F. tularensis LVS [25]. The larvae do not have an adaptive immune system, but have resistance to microbial infections via cellular and humoral defenses [26]. The analysis of insect responses to 
pathogens can provide an accurate indication of the mammalian response to that pathogen. Physical effects such as color change can be observed when the bacteria replicates and increases in the larvae [25]. We used G. mellonella as an alternative to the mouse model of Francisella infection to test our hypothesis that Az treatment could prolong the survival of Francisella infected caterpillars.

\section{Results}

\section{Francisella's sensitivity to $A z$}

It has been reported that European clinical strains of Type B F. tularensis are resistant to Az [27]. However, we observed that commonly used laboratory strains of Francisella are sensitive to Az. In vitro susceptibility testing of Az confirmed that $F$. tularensis LVS strain was not highly sensitive in vitro to this antibiotic, confirming that the Type B strains are relatively resistant to this antibiotic. Our study demonstrated that $F$. philomiragia, F. novicida and Type A F. tularensis tularensis, including both $F$. tularensis tularensis $\mathrm{NIH}$ B38 and $F$. tularensis Schu S4 strains, were susceptible to this drug in vitro and in vivo.

Francisella strains were tested in a Kirby-Bauer disc inhibition assay for sensitivity to Az. F. novicida, F. philomiragia, and $F$. tularensis tularensis B38 were sensitive to $15 \mu \mathrm{g} \mathrm{Az} \mathrm{discs,} \mathrm{whereas} F$. tularensis LVS was not sensitive to this concentration. F. novicida had a zone of inhibition of $28.7 \pm 0.7 \mathrm{~mm}$ in diameter around the $6 \mathrm{~mm} \mathrm{Az}$ disc, and $F$. philomiragia's zone of inhibition was $21.7 \pm$ $0.8 \mathrm{~mm}$ in diameter. F. tularensis tularensis NIH B38 had the largest zone of inhibition, $45.9 \pm 6.2 \mathrm{~mm}$ in diameter around the Az disc (Table 1). These results were all significantly different than $F$. tularensis LVS (p-value $<0.001$ ). Although F. tularensis tularensis NIH B38 is not virulent, this result suggested the potential sensitivity of the Type A strains to Az. In order to corroborate this with the fully virulent strain, F. tularensis Schu S4 was tested and deter- mined to have a zone of inhibition of $25.5 \pm 1.9 \mathrm{~mm}$ (pvalue $<0.001$ compared to $F$. tularensis LVS).

The Minimal Inhibitory Concentrations (MIC) for $\mathrm{Az}$ and gentamicin were measured in liquid broth assays to determine Francisella sensitivity to Az compared to control antibiotic gentamicin. F. novicida and F. philomiragia were more susceptible to Az than F. tularensis LVS, which was only susceptible to $\mathrm{Az}$ at higher concentrations. The MIC of Az for $F$. novicida is $0.78 \mu \mathrm{g} / \mathrm{ml}\left(\mathrm{EC}_{50}\right.$ of $0.16 \mu \mathrm{g} /$ $\mathrm{ml})$, and $1.56 \mu \mathrm{g} / \mathrm{ml}\left(\mathrm{EC}_{50}\right.$ of $\left.0.13 \mu \mathrm{g} / \mathrm{ml}\right)$ for F. philomiragia. These results were all significantly different than $F$. tularensis LVS (MIC of $25.0 \mu \mathrm{g} / \mathrm{ml} ; \mathrm{EC}_{50}$ of $17.3 \mu \mathrm{g} / \mathrm{ml}$; pvalue $\leq$ 0.004) (Figure 2, Table 2). The MIC result for $F$. tularensis LVS explains why there was no inhibition of growth in the disc-diffusion assay, as there was only $15 \mu \mathrm{g}$ of $\mathrm{Az}$ in the disc, which is below the MIC and the $\mathrm{EC}_{50}$. Our studies were performed with Francisella LVS strain NR-646 from BEI Resources, who state that it has been confirmed by PCR amplification of a sub-species specific sequence to be subsp. holarctica (Type B). Our results differ from those reported by Ikaheimo et al. for the Type B ATCC 29684, deposited in BEI as Francisella LVS NR14, who reported a MIC for azithromycin of $>256 \mathrm{mg} / \mathrm{L}$ [27]. Results for F. tularensis Schu S4 were similar to $F$. novicida with a MIC of $0.78 \mu \mathrm{g} / \mathrm{ml}$, and $\mathrm{EC}_{50}$ of $0.15 \mu \mathrm{g} /$ $\mathrm{ml} \mathrm{Az}$ (Table 2). This is consistent with the disc inhibition assay results. These results are also similar to results with related macrolide antibiotic, erythromycin, which has a reported MIC of 0.5-4, and $\mathrm{EC}_{50}$ of $2 \mu \mathrm{g} / \mathrm{ml}$ against Type A and B Francisella strains, though not LVS (MIC > 256 $\mu \mathrm{g} / \mathrm{ml}$ ) [28]. As a control, we determined the MIC for the antibiotic gentamicin to which all strains of Francisella are susceptible [29]. The MIC of gentamicin for $F$. novicida was determined to be $0.2 \mu \mathrm{g} / \mathrm{ml}\left(\mathrm{EC}_{50}\right.$ of $\left.0.12 \mu \mathrm{g} / \mathrm{ml}\right)$; for F. philomiragia the MIC was $0.39 \mu \mathrm{g} / \mathrm{ml}\left(\mathrm{EC}_{50}\right.$ of 0.22 $\mu \mathrm{g} / \mathrm{ml})$; and for F. tularensis LVS the MIC was $0.39 \mu \mathrm{g} / \mathrm{ml}$

Table 1: Az Disk Inhibition Assay with Francisella strains.

\begin{tabular}{|c|c|c|}
\hline Bacterial Strains & Antibiotic Zone of Inhibition ( $\mathrm{mm}$ ) (Disc is $6 \mathrm{~mm}$ ) & p-value \\
\hline F. tularensis LVS & $6.0 \pm 0$ & ---- \\
\hline F. novicida & $28.7 \pm 0.7$ & $<0.001$ \\
\hline F. philomiragia & $21.7 \pm 0.8$ & $<0.001$ \\
\hline F. tularensis NIH B38 & $45.9 \pm 6.2$ & $<0.001$ \\
\hline F. tularensis Schu S4 & $25.5 \pm 1.9$ & $<0.001$ \\
\hline
\end{tabular}

$15 \mu \mathrm{g} \mathrm{Az}$ discs (Fluka) were placed on the agar and the zone of inhibition was measured. P-value was calculated compared to $F$. tularensis LVS. 
Table 2: MIC Assay of Az for Francisella strains.

\begin{tabular}{|c|c|c|c|c|c|}
\hline Bacteria & Az MIC $(\mu \mathrm{g} / \mathrm{ml})$ & $A z E C_{50}(\mu \mathrm{g} / \mathrm{ml})$ & p-value & Gent MIC ( $\mu \mathrm{g} / \mathrm{ml})$ & Gent $\mathrm{EC}_{50}(\mu \mathrm{g} / \mathrm{ml})$ \\
\hline F. tularensis LVS & 25 & 17.34 & ---- & 0.39 & 0.09 \\
\hline F. philomiragia & 1.56 & 0.13 & $<0.001$ & 0.39 & 0.22 \\
\hline F. novicida & 0.78 & 0.16 & $<0.001$ & 0.20 & 0.12 \\
\hline F. tularensis Schu S4 & 0.78 & 0.1453 & 0.004 & $\mathrm{n} / \mathrm{a}$ & $\mathrm{n} / \mathrm{a}$ \\
\hline
\end{tabular}

The $\mathrm{p}$-value is for comparisons of the $\mathrm{EC}_{50}$ values.

$\left(\mathrm{EC}_{50}\right.$ of $0.09 \mu \mathrm{g} / \mathrm{ml}$ ) (Table 2). These values are consistent with published sensitivities of Type B strains (MIC of 0.03-0.5 $\mu \mathrm{g} / \mathrm{ml}, \mathrm{EC}_{50}$ of $0.12 \mu \mathrm{g} / \mathrm{ml}$ ) [28]. Thus, the Type A Francisella tularensis SchuS4, F. novicida and F. philomiragia are all sensitive to $\mathrm{Az}$ in vitro. Type $\mathrm{B}$ Francisella LVS was also determined to be sensitive, but at a higher concentration of Az.

J774A.1 and A549 cells were infected with Francisella and treated with Az. The same multiplicity of infection $(\mathrm{MOI}=500)$ was used, based on previous studies for Francisella infection [30]. Cells were lysed and bacteria were recovered and counted as colony forming units (CFU). Francisella-infected J774A.1 and A549 cells were found to have more than $105 \mathrm{CFU} / \mathrm{ml}$ of Francisella after 22 hours after infection. J774A.1 cells infected with Francisella and treated with Az had decreasing CFUs as the

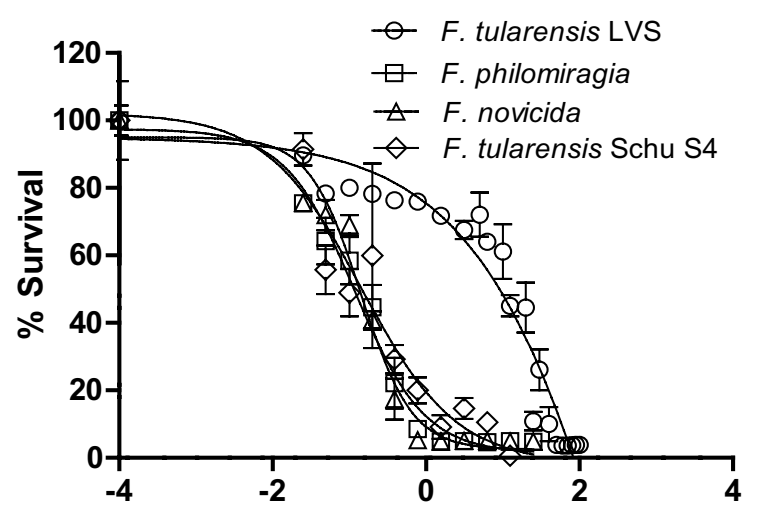

Azithromycin Concentration $(\log \mu \mathrm{g} / \mathrm{ml})$

Figure $\mathbf{2}$ MIC determination of Az for F. tularensis LVS, F. philomiragia, F. novicida, and F.tularensis Schu S4. Az MIC for F. tularensis LVS (circles) is higher than F. philomiragia (squares), F. novicida (up triangle), and F. tularensis Schu S4 (down triangle). Az MICs for F. novicida and F. tularensis Schu S4 are $0.78 \mu \mathrm{g} / \mathrm{ml}$ with an $\mathrm{EC}_{50}$ of $0.16 \mu \mathrm{g} / \mathrm{ml}$ and $0.15 \mu \mathrm{g} / \mathrm{ml}$ respectively. F. philomiragia's Az MIC is $1.56 \mu \mathrm{g} / \mathrm{ml}$ with an $\mathrm{EC}_{50}$ of $0.13 \mu \mathrm{g} / \mathrm{ml}$, and F. tularensis LVS's Az MIC is $25 \mu \mathrm{g} / \mathrm{ml}$ with an $\mathrm{EC}_{50}$ of $17.34 \mu \mathrm{g} / \mathrm{ml}$. antibiotic concentration increased. In J774A.1 cells infected with F. philomiragia, no CFUs were recovered when treated with $0.1 \mu \mathrm{g} / \mathrm{ml} \mathrm{Az}$ (less than the MIC). In J774A.1 cells infected with either F. novicida or F. tularensis LVS, bacterial concentrations decreased with the addition of Az. At $5 \mu \mathrm{g} / \mathrm{ml} \mathrm{Az}$, no CFUs were recovered (pvalue $<0.005$ compared to $0 \mu \mathrm{g} / \mathrm{ml} \mathrm{Az}$ ) (Figure 3A). In this case, the Az concentration was less than the MIC for F. tularensis LVS. Francisella-infected A549 cells required higher concentrations of $\mathrm{Az}$ than J774A.1 cells, suggesting that epithelial cells are not able to concentrate Az in the same manner as macrophages. As before, intracellular F. novicida, F. philomiragia, and F. tularensis LVS CFU counts decreased when A549 cells were treated with Az. Recovered intracellular CFU counts for F. philomiragia and $\mathrm{F}$. novicida remained approximately equal when treated with 0.1 and $5 \mu \mathrm{g} / \mathrm{ml} \mathrm{Az}$ (p-value > 0.05), but strongly decreased at $25 \mu \mathrm{g} / \mathrm{ml} \mathrm{Az}$ (p-value $<0.005 \mathrm{com}$ pared to $0 \mu \mathrm{g} / \mathrm{ml} \mathrm{Az}$ ). For these two organisms, the required external antibiotic concentration was higher than the in vitro MIC. F. tularensis LVS infected A549 cells had a steady decline of intracellular CFU counts as the Az concentration increased and had essentially no colonies recovered at $25 \mu \mathrm{g} / \mathrm{ml}$ extracellular Az (p-value < 0.005 compared to $0 \mu \mathrm{g} / \mathrm{ml} \mathrm{Az}$ ), which is equivalent to the MIC for that strain (Figure 3B). The difference between the cell types may reflect the fact that J774A.1 cells are phagocytic macrophages, and the A549 cells are nonphagocytic epithelial cells.

To determine if Francisella bacteria counts were decreased due to Az concentrations or due to cell death, cellular lysis and apoptosis were measured by LDH released [19]. At 22 hours, cell cytotoxicity in noninfected A549 cells and A549 cells infected with F. novicida, F. philomiragia, and F. tularensis LVS remained below 20\%. Non-infected A549 cells along with F. philomiragia, F. novicida, and F. tularensis LVS-infected cells had a slightly increased cytotoxicity as Az concentrations increased (Table 3). Cellular apoptosis remained low with all Az doses. These results suggest the decreased Franci- 


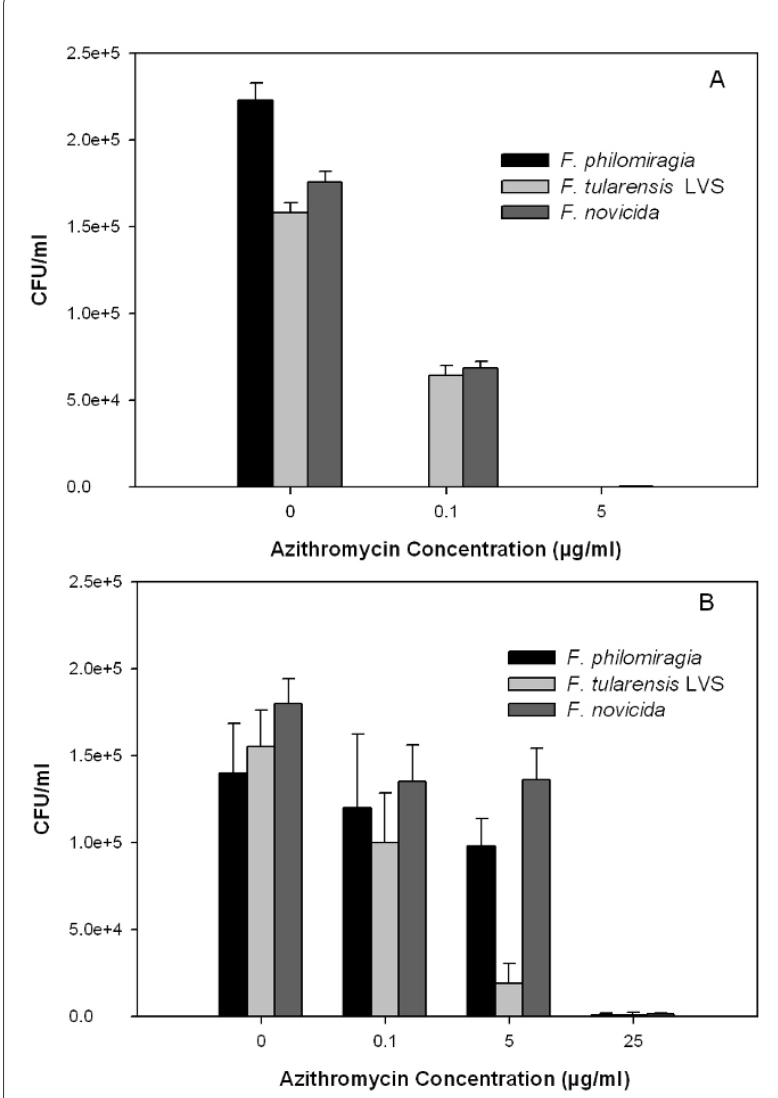

Figure 3 Az inhibition of intracellular Francisella strains. After 22 hours, recovered bacterial counts were measured for F. philomiragia, $F$. novicida, and F. tularensis LVS infected cells (MOI 500). A) J774A.1 cells infected with F. philomiragia, F. novicida, or F. tularensis LVS had more than $10^{5} \mathrm{CFU} / \mathrm{ml}$. Bacterial counts decreased for all strains as the $\mathrm{Az}$ concentrations increased and were near 0 CFU/ml at $5 \mu \mathrm{g} / \mathrm{ml} \mathrm{Az}$. B) A549 cells infected with F. philomiragia, F. novicida, or F. tularensis LVS had more than $10^{5} \mathrm{CFU} / \mathrm{ml}$ at $0 \mu \mathrm{g} / \mathrm{ml}$ Az. Bacterial counts decreased at 0.1 and $5 \mu \mathrm{g} / \mathrm{ml} \mathrm{Az}$ and were near 0 CFU $/ \mathrm{ml}$ at $25 \mu \mathrm{g} / \mathrm{ml} \mathrm{Az}$. CFU counts from no Az treatment compared $0.1,5$, and $25 \mu \mathrm{g} / \mathrm{ml}$ Az treatment for all Francisella strains were significantly different ( $p$-value $<$ 0.005).

sella counts were due to Az treatment and not due to bacterial release during the experiment from apoptosis or cell lysis.

\section{Francisella LPS mutants}

Due to the potential for interaction of Az with LPS [9], four $F$. novicida transposon LPS O-antigen mutants were tested for their Az susceptibility: O-antigen of LPS (wbtA) biosynthesis of GdNAcAN, an O-antigen unit ( $w b t E)$, glycosylatransferase that elongates to form GalNAcAN trisaccharides (wbtQ), and aminotransferase (wbtN) [10]. F. novicida LPS O-antigen mutants including $w b t A, w b t E$, $w b t Q$, and $w b t N$ were shown to be less susceptible to $\mathrm{Az}$ by decreased zones of inhibition in comparison to the wild-type (p-value < 0.001) (Table 4). The MICs for Az against the $F$. novicida LPS-related transposon mutants $w b t A, w b t E$, $w b t Q$, and $w b t N$ (MIC's $>3.0 \mu \mathrm{g} / \mathrm{ml} \mathrm{Az}, \mathrm{EC}_{50}$ $>0.50 \mu \mathrm{g} / \mathrm{ml} \mathrm{Az}$ ) were greater than the wild-type MIC $(0.78 \mu \mathrm{g} / \mathrm{ml})$ (p-value $<0.005)$ (Figure 4A, Table 5), suggesting increased resistance to Az. These data are consistent with the disc inhibition studies, suggesting that Francisella LPS plays some role in the sensitivity of the strains for Az.

\section{Francisella RND mutants}

Five $F$. novicida transposon insertion mutants in the multidrug efflux protein genes ( $a c r A$ and $a c r B$ ), the transcriptionally linked protein gene $(d s b B)$, as well as the related outer membrane channel genes (tolC and $f t l C$ ) were tested to determine if $\mathrm{Az}$ susceptibility increases or decreases [12]. Results for the RND efflux mutants varied among the different subspecies (Table 6). In the disc inhibition assay, the tolC mutant was slightly more sensitive to Az compared to the wild-type $F$. novicida (p-value = 0.007), while $f t l C$, $a c r A$, and $a c r B$ were less susceptible to Az compared to the wild-type (p-value $<0.01$ ) (Table 6). The MICs for $f t l C$, tolC, $a c r A$, and $a c r B$ (MIC $=25 \mu \mathrm{g} / \mathrm{ml}$ $\mathrm{Az}$ ) were greater than the wild-type (MIC of $0.78 \mu \mathrm{g} / \mathrm{ml}$ $\mathrm{Az})$ and had a higher $\mathrm{EC}_{50}\left(\mathrm{EC}_{50}>12 \mu \mathrm{g} / \mathrm{ml} \mathrm{Az}\right) \mathrm{com}-$ pared to the wild-type of $0.16 \mu \mathrm{g} / \mathrm{ml} \mathrm{Az}$ (p-value $<0.002$ ), indicating decreased sensitivity to the antibiotic. These results are consistent between the MIC and disc inhibition assay for $a c r A, a c r B$, and $f t l C$ (Figure 4B, Table 5). The tolC sensitivity to Az results in the solid agar and liquid broth assay were inconsistent. The disc-inhibition assay suggests increased sensitivity, while the MIC assay demonstrated increased resistance. We are currently investigating the basis of this difference.

In the disc inhibition assay of the disulfide bond protein mutant $d s b B$, there was no significant difference compared to the wild-type $(p-v a l u e=0.162)($ Table 6). Similarly, the MIC for $d s b B$ was not significantly different than the wild-type value ( $\mathrm{p}$-value $=0.400)$ (Table 5). Thus, mutation of $d s b B$ does not seem to have a significant impact on the ability of the organism to resist Az, whereas transposon insertion mutants in the $t o l C, f t l C$, acrA and $a c r B$ components of the RND efflux system appear to decrease the sensitivity of $F$. novicida to Az. This result for $t o l C$ and $f t l C$ may be in contrast to Gil et al. [12], who found that $F$. tularensis LVS deletion of tolC or $\mathrm{ftlC}$ did not alter the sensitivity to erythromycin $(15 \mu \mathrm{g}$ disc). The MIC of $F$. tularensis LVS is higher than can be achieved using a $15 \mu \mathrm{g}$ disc, reported at $>256 \mu \mathrm{g} / \mathrm{ml}$ erythromycin [28]. Therefore, any alteration in sensitivity due to $t o l C$ deletion would not be observed at this low concentration of antibiotic.

In contrast to the $F$. novicida results, the $F$. tularensis Schu S4 $\triangle a c r A$ mutant and $\triangle a c r B$ mutants had greater sensitivity to Az compared to the wild-type F. tularensis 
Table 3: A549 cell cytotoxicity.

\begin{tabular}{|c|c|c|c|c|c|}
\hline Bacteria & $0 \mu \mathrm{g} / \mathrm{ml}$ Az & $0.1 \mu \mathrm{g} / \mathrm{ml} \mathrm{Az}$ & $1.0 \mu \mathrm{g} / \mathrm{ml} \mathrm{Az}$ & $2.5 \mu \mathrm{g} / \mathrm{ml} \mathrm{Az}$ & $5.0 \mu \mathrm{g} / \mathrm{ml} \mathrm{Az}$ \\
\hline A549 cells & $0 \pm 3.0$ & $2.9 \pm 2.8$ & $8.0 \pm 4.0$ & $18.3 \pm 5.2$ & $19.7 \pm 9.6$ \\
\hline F. novicida & $0 \pm 2.3$ & $4.1 \pm 5.0$ & $3.3 \pm 6.3$ & $9.6 \pm 5.4$ & $17.8 \pm 13.2$ \\
\hline F. philomiragia & $0 \pm 1.3$ & $0 \pm 2.5$ & $7.1 \pm 4.6$ & $1.7 \pm 3.2$ & $8.5 \pm 4.1$ \\
\hline F. tularensis LVS & $0 \pm 3.7$ & $2.12 \pm 5.0$ & $4.6 \pm 5.9$ & $8.4 \pm 5.1$ & $5.2 \pm 5.6$ \\
\hline
\end{tabular}

Schu S4 (p-value < 0.001) (Table 6). This is consistent with the findings of Qin et al. [16] who found an increased sensitivity of $\triangle a c r B$ to $50 \mu$ g disc erythromycin. The MICs for Az against F. tularensis Schu S4 RND efflux mutants were also determined. The MICs for $\triangle a c r A$ and $\triangle a c r B$ (MIC $>1.5 \mu \mathrm{g} / \mathrm{ml} \mathrm{Az}$ ) are higher than the wildtype MIC of $0.78 \mu \mathrm{g} / \mathrm{ml} \mathrm{Az}$ (p-value < 0.02) (Figure 4C, Table 5). However, the $F$. tularensis Schu S4 mutants for $\triangle a c r A\left(\mathrm{EC}_{50}\right.$ of $\left.0.085 \mu \mathrm{g} / \mathrm{ml}\right)$ and $\triangle a c r B\left(\mathrm{EC}_{50}\right.$ of $0.049 \mu \mathrm{g} /$ $\mathrm{ml}$ ) have $\mathrm{EC}_{50} \mathrm{~s}$ less than the wild-type $F$. tularensis Schu S4 $\left(\mathrm{EC}_{50}\right.$ of $\left.0.145 \mu \mathrm{g} / \mathrm{ml}\right)$, reflecting the altered shape of the MIC curve and indicating increased sensitivity. Only $\triangle a c r B$ was statistically significantly different for $\mathrm{EC}_{50}$ when compared to the wild-type F. tularensis Schu S4 (pvalue $<0.05$ ). Thus, F. tularensis Schu S4 $\triangle a c r A$ and $\triangle a c r B$ mutants had greater sensitivity to Az compared to F. novicida mutants, or the parental F. tularensis Schu S4 strain by disc inhibition assay and MIC.

Az inhibition of intracellular Francisella mutant strains J774A.1 and A549 cells infected with F. novicida transposon LPS mutant $w b t A$ and multidrug efflux mutants $f t l C$,
tolC, acr $A$, and $a c r B$ had more than $10^{4} \mathrm{CFU} / \mathrm{ml} 22$ hours post-infection (Figure 5). $\mathrm{ftlC}$ generally had lower CFU counts, whereas the $a c r A$ and $a c r B$ had higher CFU counts in both cell lines. The CFU of $F$. novicida transposon mutants decreased as the Az concentration increased for each cell line ( $\mathrm{p}$-value $<0.005$ for each Az treatment compared to $0 \mu \mathrm{g} / \mathrm{ml} \mathrm{Az}$ ). At $35 \mu \mathrm{g} / \mathrm{ml} \mathrm{Az} \mathrm{treatment,} \mathrm{the}$ bacterial CFU count was near $0 \mathrm{CFU} / \mathrm{ml}$ in J774A.1 and A549 cells (Figure 5). Thus, $w b t A$ and the RND mutants are capable of replication within J774A.1 and A549 cells, although the overall number of bacteria per cell was lower than for the parental $F$. novicida infection $(1.76 \times$ $10^{5} \pm 6.36 \times 10^{3} \mathrm{CFU} / \mathrm{ml}$ in J774A. 1 and $1.80 \times 10^{5} \pm 1.41$ $\times 10^{4} \mathrm{CFU} / \mathrm{ml}$ in A549 cells at $\left.0 \mu \mathrm{g} / \mathrm{ml}\right)$. Mutant trends after Az treatments were significantly different from the wild-type $F$. novicida with a p-value $<0.05$ (wild-type decreased to $0 \mathrm{CFU} / \mathrm{ml}$ at $5 \mu \mathrm{g} / \mathrm{ml} \mathrm{Az}$ in J774A.1 cells and decreased to $0 \mathrm{CFU} / \mathrm{ml}$ at $25 \mu \mathrm{g} / \mathrm{ml} \mathrm{Az}$ in A549 cells). Corresponding to the higher MICs identified in vitro, LPS mutants require more Az to eliminate the bacteria from infected cells.

Table 4: Az Disk Inhibition Assay with Francisella transposon mutants of LPS production genes.

\begin{tabular}{lcc}
\hline & \multicolumn{2}{c}{ Antibiotic No Growth Zone (mm) } \\
\hline F. novicida & Avg & P-value \\
\hline wild-type & $28.7 \pm 0.7$ & - \\
\hline wbtA & $20.8 \pm 0.5$ & $<0.001$ \\
\hline wbtN & $23.3 \pm 0$ & $<0.001$ \\
\hline wbtE & & $<0.001$ \\
\hline wbtQ & $23.0 \pm 0.9$ & $<0.001$ \\
\hline
\end{tabular}

$15 \mathrm{ug} \mathrm{Az}$ discs from Fluka were placed on an agar plate spread with the indicated strain. The zone of inhibition was measured in mm. 
Table 5: MIC Assay of Az for F. novicida transposon mutants.

\begin{tabular}{|c|c|c|c|}
\hline Bacteria & AZ MIC $(\mu \mathrm{g} / \mathrm{ml})$ & $A Z E C_{50}(\mu \mathrm{g} / \mathrm{ml})$ & p-value \\
\hline F. novicida & 0.78 & 0.16 & ----- \\
\hline wbtQ & 3.12 & 0.52 & 0.005 \\
\hline wbtN & 12.5 & 0.54 & $<0.002$ \\
\hline wbtE & 25 & 0.50 & $<0.001$ \\
\hline$w b t A$ & 12.5 & 0.67 & 0.007 \\
\hline$d s b B$ & 1.56 & 0.16 & 0.401 \\
\hline $\mathrm{ft} / \mathrm{C}$ & 25 & 13.47 & $<0.002$ \\
\hline tolC & 50 & 16.44 & $<0.001$ \\
\hline$a c r A$ & 50 & 12.39 & $<0.001$ \\
\hline$a c r B$ & 50 & 13.23 & 0.001 \\
\hline F. tularensis Schu S4 & 0.78 & 0.1453 & ----- \\
\hline$\triangle a c r A$ & 3.13 & 0.0852 & 0.087 \\
\hline$\Delta a c r B$ & 1.56 & 0.0493 & 0.031 \\
\hline
\end{tabular}

\section{G. mellonella infection by Francisella and antibiotic treatment}

Francisella-infected G. mellonella was used as a model system [25] to study Az treatment. G. mellonella were infected with either $3 \times 10^{6} \mathrm{CFU}$ bacteria/larva of $F$. novicida or F. tularensis LVS and then treated with a single dose of $10 \mu \mathrm{l}$ injections PBS (no antibiotic), $20 \mu \mathrm{g} / \mathrm{ml}$ ciprofloxacin, or $25 \mu \mathrm{g} / \mathrm{ml} \mathrm{Az}$. Control groups (no infection) consisted of no injections, injections of either PBS (to measure trauma related to injections), $20 \mu \mathrm{g} / \mathrm{ml}$ ciprofloxacin, or $25 \mu \mathrm{g} / \mathrm{ml} \mathrm{Az}$ (to assess antimicrobial agent effects on the host). All controls had similar survival rates (data not shown for antibiotic injection only controls). Francisella-infected G. mellonella did not survive past 100 hours post-infection. Control groups survived for more than 300 hours. Infected groups treated with a single dose $20 \mu \mathrm{g} / \mathrm{ml}$ ciprofloxacin (mean time to death $>74$ hours) or $25 \mu \mathrm{g} / \mathrm{ml} \mathrm{Az}$ (mean time to death > 160 hours) had a statistically significant prolonged survival times when compared to infected groups ( $\mathrm{p}$-value $<0.005)$ (Figure $6 \mathrm{~A} \& 6 \mathrm{~B})$. These results are consistent with previously published results of G. mellonella infected with $F$. tularensis LVS and treated with $20 \mu \mathrm{g} / \mathrm{ml}$ ciprofloxacin [25]. Although we could not achieve complete recovery, Francisella-infected G. mellonella groups treated with Az had an increased mean survival time compared to ciprofloxacin-treated caterpillars ( $\mathrm{p}$-value $<0.02)$.

\section{Discussion}

The macrolide erythromycin has limited efficacy against many gram-negative bacteria due to its hydrophobic nature and lack of permeability of the gram-negative outer membrane [31]. The sensitivity of erythromycin varies between Francisella strains. In the North American Type A Francisella strains, erythromycin MICs range from 0.5 to $4 \mu \mathrm{g} / \mathrm{ml}$, while F. tularensis LVS has an MIC > $256 \mu \mathrm{g} / \mathrm{ml}$ [32]. The macrolide azithromycin is more effective against gram-negative bacteria than erythromycin [33]. Despite reports that European clinical strains of Type B F. tularensis are resistant to Az (MIC > $256 \mathrm{mg} / \mathrm{L}$ ) [27], we observed that commonly used laboratory strains were sensitive to Az. In this study, we have demonstrated 

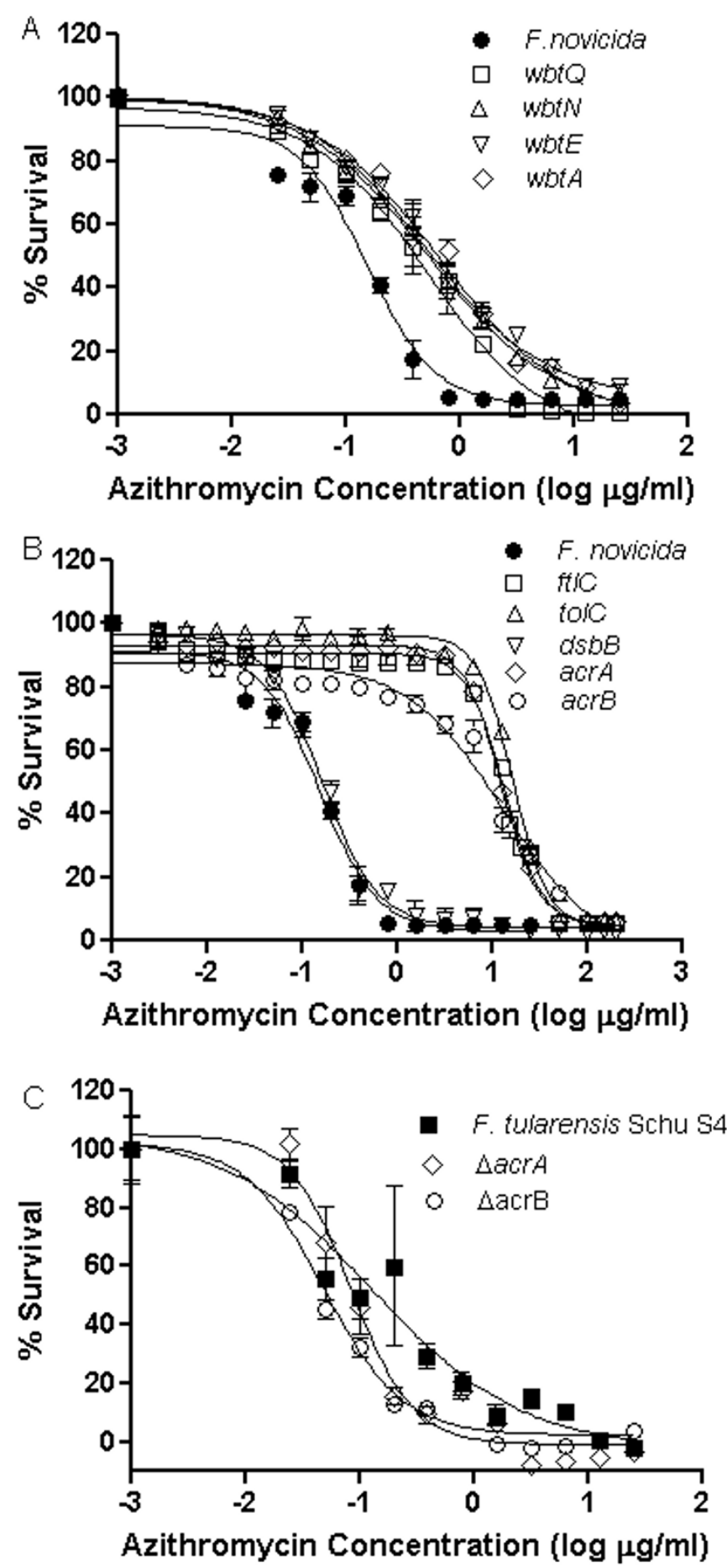

Figure 4 MIC determination of Az for F. novicida transposon LPS and RND efflux mutants and F. tularensis Schu S4 RND efflux mutants. A) The MIC of Az for LPS O-antigen F. novicida transposon mutants was generally higher than the wild-type (circle) MIC of 0.78 $\mu \mathrm{g} / \mathrm{ml}$. MICs for LPS Oantigen mutants were $12.5 \mu \mathrm{g} / \mathrm{ml}$ for $w b t A$ (diamond), $25.0 \mu \mathrm{g} / \mathrm{ml}$ for wbtE (down triangle), $3.12 \mu \mathrm{g} / \mathrm{ml}$ for wbtQ (square), and $12.5 \mu \mathrm{g} / \mathrm{ml}$ for wbtN (triangle), with an $\mathrm{EC}_{50}$ for all LPS O-antigen mutants greater than $0.50 \mathrm{\mu g} / \mathrm{ml}$ (p-value < 0.005). B) MICs for F. novicida transposon-insertion RND efflux mutant varied: $d s b B$ (down triangle) was closer to the wild-type (closed circle) at $1.56 \mu \mathrm{g} / \mathrm{ml}$ (p-value 0.400). ft/C, tolC, acrA, and acrB have greater MIC with $25 \mu \mathrm{g} / \mathrm{ml}$ for $\mathrm{ft} / \mathrm{C}$ (square) and $50 \mathrm{\mu g} / \mathrm{ml}$ for to/C (up triangle), $a c r A$ (diamond), and acrB (open circle), with EC $C_{50} \mathrm{greater}$ than $12 \mu \mathrm{g} / \mathrm{ml}$ ( $\mathrm{p}$-value $<$ 0.005). C) The MICs of Az for F. tularensis Schu S4 (square) and deletion RND efflux mutants. F. tularensis Schu S4 (square) has an MIC of $0.78 \mu \mathrm{g} / \mathrm{ml}$, $\triangle a c r B$ (circle) of $1.56 \mu \mathrm{g} / \mathrm{ml}$, and $\triangle a c r A$ (diamond) of $3.13 \mu \mathrm{g} / \mathrm{ml}$. F. tularensis Schu S4 and mutants all have $\mathrm{EC}_{50}$ less than $0.15 \mu \mathrm{g} / \mathrm{ml}$ ( $\mathrm{p}$-value $<0.1 \mathrm{for}$ $\triangle a c r A$ and $\triangle a c r B$ compared to wild-type). 
Table 6: Az Disk Inhibition Assay with Francisella transposon RND Efflux mutants.

\begin{tabular}{|c|c|c|}
\hline \multirow[b]{2}{*}{ F. novicida } & \multicolumn{2}{|c|}{ Antibiotic No Growth Zone (mm) } \\
\hline & Avg & p-value \\
\hline wild-type & $31.4 \pm 1.0$ & \\
\hline$f t / C$ & $28.0 \pm 3.1$ & 0.006 \\
\hline tolc & $33.2 \pm 1.4$ & 0.007 \\
\hline$d s b B$ & $30.7 \pm 1.2$ & 0.162 \\
\hline$a c r A$ & $23.5 \pm 0.7$ & $<0.001$ \\
\hline$a c r B$ & $25.2 \pm 1.1$ & $<0.001$ \\
\hline F. tularensis Schu S4 & Avg & p-value \\
\hline wild-type & $25.5 \pm 1.9$ & ------- \\
\hline$\triangle a c r A$ & $41.7 \pm 2.7$ & 0.0001 \\
\hline$\triangle a c r B$ & $35.7 \pm 4.3$ & 0.001 \\
\hline
\end{tabular}

that the Type A F. tularensis tularensis strains are sensitive to Az in vitro. F. philomiragia and F. novicida are also sensitive with similar MICs. We determined that the MIC for F. tularensis LVS (NR-646) was $25 \mathrm{ug} / \mathrm{ml} \mathrm{Az,} \mathrm{confirm-}$ ing the finding that LVS is relatively more resistant to $\mathrm{Az}$ than other Francisella strains.

$\mathrm{Az}$ is pumped out of gram-negative bacteria by several drug-efflux systems, including the RND efflux pumps. Az sensitivity differed between $F$. novicida and F. tularensis Schu S4 RND efflux mutants. Wild-type F. tularensis Schu S4 has similar sensitivity to Az as wild-type F. novicida, but the RND efflux mutants $\triangle a c r A$ and $\triangle a c r B$ in $F$. tularensis Schu S4 are more sensitive to $\mathrm{Az}$, whereas the $F$. novicida acr $A$ and acr $B$ mutants are more resistant. These F. tularensis Schu S4 $\triangle a c r A$ and $\triangle a c r B$ mutants were also reported to be more sensitive to the related antibiotic erythromycin [16]. The difference between the F. tularensis Schu S4 and the F. novicida mutants might be due to the fact that F. tularensis Schu S4 has 254 pseudogenes; many of these genes are intact in F. novicida [34]. For example, in F. tularensis Schu S4, at least 14 genes of the MFS transporter superfamily contain stop codons or frameshifts [34,35] and are thus predicted to be non-functional. Additional types of transporter proteins, including a drug-resistance transporter (FTT1618), are also reported to be non-functional pseudogenes [34] in $F$. tularensis Schu S4. It could be that the remaining TolCAcrAB pump is the major means by which F. tularensis Schu S4 pumps out Az. If this pump is compromised, the organism would be more susceptible to the antibiotic, because it may not have an operational alternative pump, such as the MFS or ABC transporters to pump out the drug. This is supported by the finding that $\triangle a c r A$ and $\triangle a c r B$ mutants in F. tularensis Schu S4 also displayed increased sensitivity to nalidixic acid (a substrate for the MFS transporter), as well as detergents, streptomycin, tetracycline, and other molecules [16]. In the case of $F$. novicida, there may be alternate systems that can pump out the drug in the absence of the RND system. Alternatively, the mutation in $a c r A$ or $a c r B$ may cause an up-regulation of expression of another drug-efflux pump, rendering the bacteria more resistant to the antibiotic $[36,37]$. Previous studies have shown that $d s b B$ mutant in F. tularensis Schu S4 does not have any effect on antibiotic sensitivity (including the macrolide erythromycin) [16]. Consistent with the F. tularensis Schu S4 $d s b B$ mutant, the $F$. novicida $d s b B$ mutant showed no difference from the wild-type $F$. novicida. 


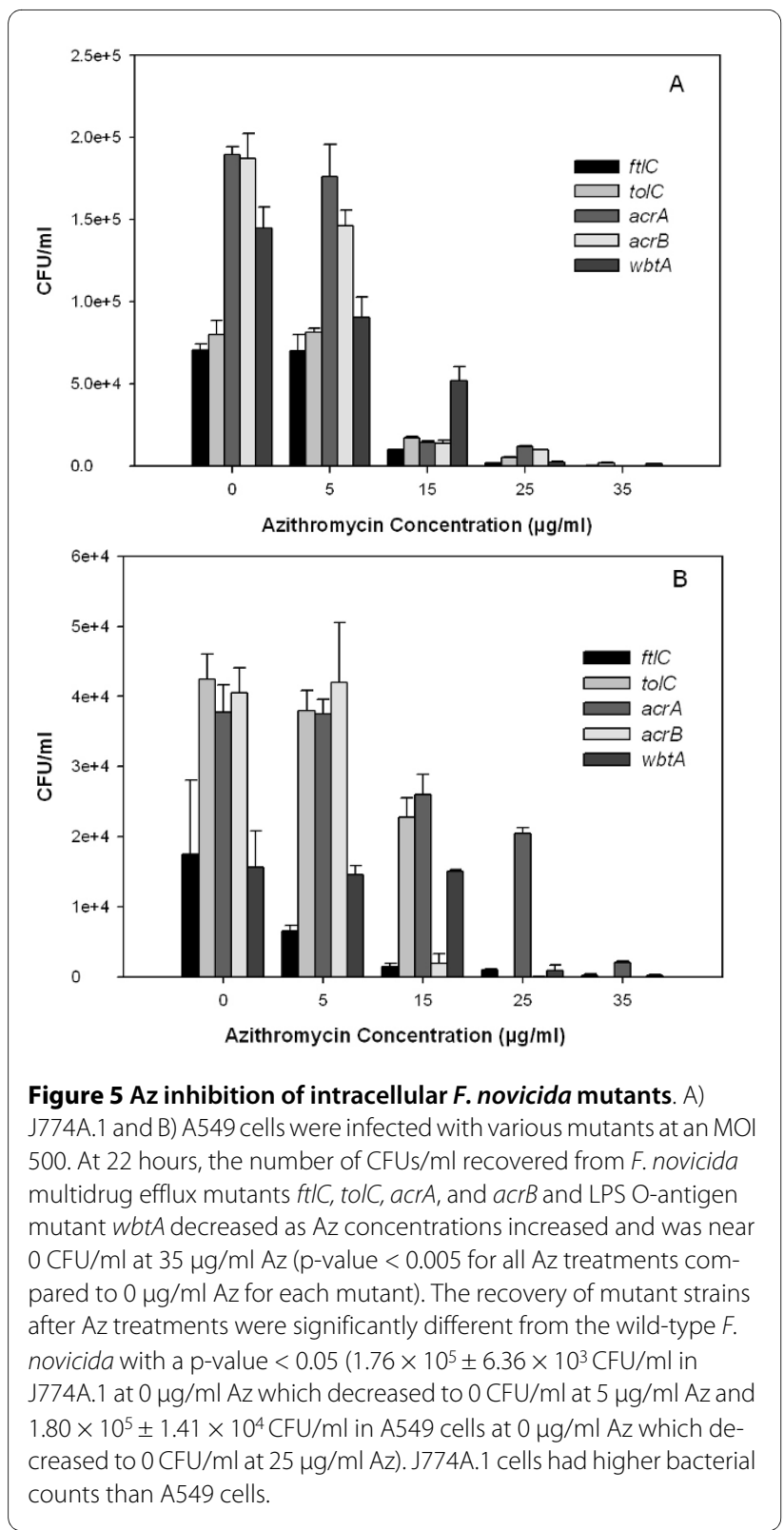

Another common mechanism of resistance to macrolides is modification of the $23 \mathrm{~S}$ rRNA. It has been reported that $F$. tularensis LVS has a point mutation in Domain $\mathrm{V}$ of the 23S rRNA, rendering it more resistant to erythromycin than F. novicida or F. tularensis Schu S4 [38]. This modification could also explain the increased resistance to Az in F. tularensis LVS. In addition, there are methylases that can confer increased resistance by targeted modification (methylation) of a specific adenine residue of the 23S rRNA. There are some methylases that have been identified as critical virulence factors for Francisella that might carry out this modification [39]. Some methylases that are present in the genome of $F$. novicida are either absent or are pseudogenes/nonfunctional genes
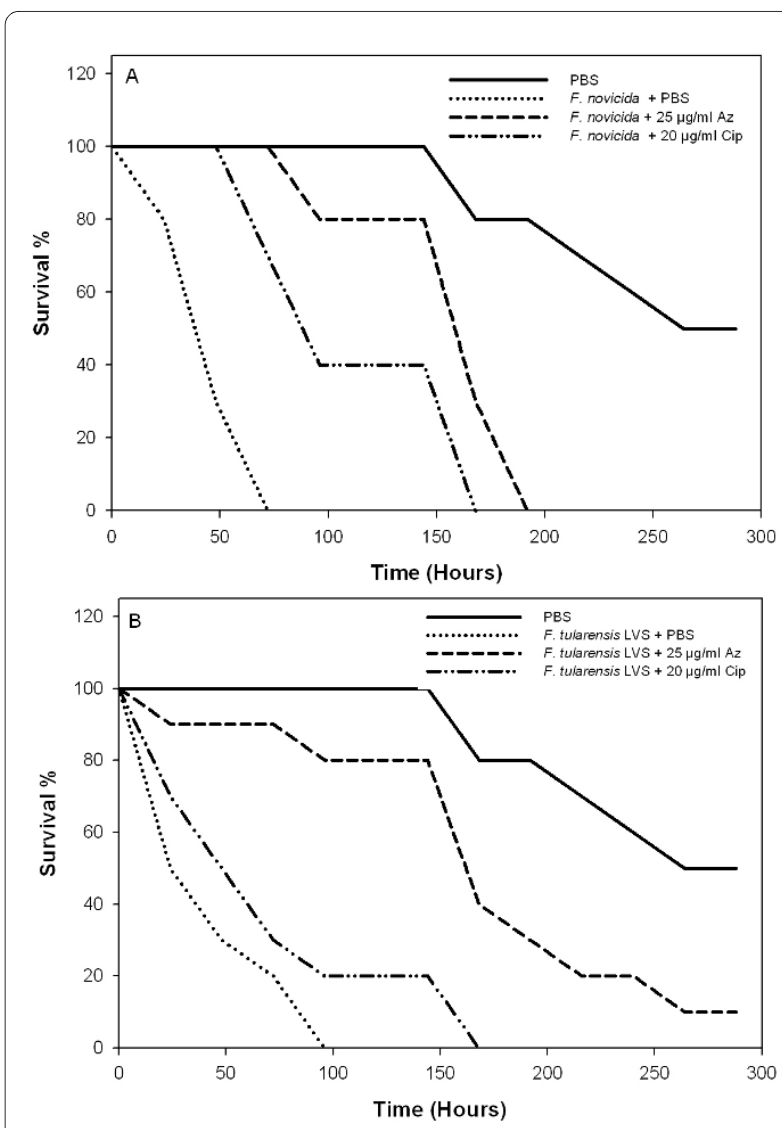

Figure 6 Antibiotic treatment of Francisella-infected G. mellonella. High concentrations of antibiotics prolonged the survival of G. mellonella infected with $3 \times 10^{6} \mathrm{CFU}$ Francisella. Non-infected control groups consisted of no injection, PBS injection, $25 \mu \mathrm{g} / \mathrm{ml}$ Az injection, or $20 \mu \mathrm{g} / \mathrm{ml}$ ciprofloxacin injection. All non-infected controls had similar high survival rates (data not shown for non-injected, $25 \mu \mathrm{g} / \mathrm{ml} \mathrm{Az}$ injection, or $20 \mu \mathrm{g} / \mathrm{ml}$ ciprofloxacin injection). A) The infected control group received F. novicida injection, then PBS. A single dose of $25 \mu \mathrm{g} /$ $\mathrm{ml} \mathrm{Az}$, given 2 hours after bacterial inoculation, was effective when compared to the infected control ( $p$-value $=0.004$ ). Treatment with 20 $\mu \mathrm{g} / \mathrm{ml}$ ciprofloxacin prolonged the survival of the caterpillars compared to the control ( $p$-value $<0.01$ ). B) The infected control group received F. tularensis LVS injection, then PBS. A single dose of $25 \mu \mathrm{g} / \mathrm{ml}$ $A z$, given 2 hours after bacterial inoculation, was effective compared to the infected control ( $p$-value $<0.001$ ). Treatment with $20 \mu \mathrm{g} / \mathrm{ml}$ ciprofloxacin prolonged the survival of the caterpillars compared to control ( $p$-value $<0.01$ ). For F. tularensis LVS and F. novicida infections, survival time was longer in $\mathrm{Az}$ treated groups compared to ciprofloxacin treated groups ( $p$-value $<0.02$ ).

(such as FTT0010, FTT0770, FTT1430, FTT1719, and FTT1735c) in F. tularensis Schu S4, potentially contributing to the different sensitivities to Az between the strains [34]. Any potential role of these molecules in Az sensitivity or resistance in Francisella has not yet been determined.

It has been suggested that $\mathrm{Az}$ attaches to the acidic LPS on the outer membrane of gram-negative bacteria, allowing the drug to penetrate through the outer membrane 
and enter the bacteria [40]. The wbt locus in Francisella, which is responsible for the production of LPS O-antigen, has been shown to be required for virulence [41]. In published reports, the wbtA mutant in $F$. tularensis LVS demonstrated a loss of the $\mathrm{O}$-antigen and an inability to replicate in mouse macrophages. F. novicida wbtA mutants replicate normally and have only moderate sensitivity to serum $[42,43]$. We tested $F$. novicida transposon-insertion mutants $w b t N$, wbtE, wbtQ and $w b t A$, which are involved in the production of LPS, and found that these mutants were less susceptible to Az. Mutations of the LPS in the F. novicida transposon LPS O-antigen mutants may alter the LPS region presumed to bind to $\mathrm{Az}$, resulting in a decreased amount of Az penetration and increased resistance to Az. Our results support the proposed role of LPS O-antigen in Az penetration into gram-negative bacteria such as Francisella.

$\mathrm{Az}$ is a weak base that can remain inside host cells for a longer time at a higher concentration than in the serum. This occurs because the basic amine groups of $\mathrm{Az}$ neutralize the lysosomal $\mathrm{pH}$ and prevent acidification of the lysosome. This process causes the drug to become trapped in the cell due to the positive charge. The drug is slowly released from polymorphonuclear neutrophils, allowing for a long half-life [8]. Az also concentrates in macrophages, which suggested to us that it might be useful as a potential treatment of intracellular pathogens such as $F$. tularensis. J774A.1 mouse macrophage were infected with F. philomiragia, F. novicida, and F. tularensis LVS and treated with Az. It was determined that $5 \mu \mathrm{g} /$ $\mathrm{ml} \mathrm{Az}$ was effective in eliminating intracellular F. philomiragia, F. novicida, and even $F$. tularensis LVS infections in J774A.1 cells. Although Type B strains are intrinsically more resistant to macrolides, $F$. tularensis LVS CFUs were eliminated below the Az MIC values for this strain. We suggest that J774A.1 cells can sufficiently concentrate $\mathrm{Az}$ so that the intramacrophage concentration of $\mathrm{Az}$ exceeds the MIC. Thus, it may be that Az is effective against LVS in vivo due to the concentration effect in macrophages. A concentration of $25 \mu \mathrm{g} / \mathrm{ml} \mathrm{Az}$ was found to be effective against Francisella infections in A549 cells, suggesting that these non-phagocytic cells may be less able to concentrate the antibiotic intracellularly [22].

Az treatment has not been tested sufficiently in the clinic to know if it can be used to treat tularemia infection. In one reported case, the patient's illness was fatal after treatment by Az, trimethoprim-sulfamethoxazole, streptomycin, and ceftriaxone of F. tularensis [44], suggesting that the patient was extremely ill when treatment was initiated. In another case, the patient's symptoms decreased with a one day ceftriaxone treatment followed by a 5 day Az treatment, but symptoms recurred after the treatment was completed [45]. There have been several reports of successful treatment with erythromycin, giving credence to the sensitivity of Type A strains to the macrolide class of antibiotics [46,47]. To test the in vivo effectiveness of $\mathrm{Az}$ against Francisella infections, we employed the wax-moth caterpillar model [25]. The timecourse of infection of the caterpillars closely matched the published report. We extended the published report by demonstrating that wax-moth caterpillars can also be infected by $F$. novicida. We demonstrated that a single injection of Az increased the mean survival time of Francisella infected G. mellonella and is more effective than a similar dose of ciprofloxacin. Within a host, macrolides, including $\mathrm{Az}$, inhibit the production of cytokines that cause inflammation and prevent the accumulation of neutrophils, which suggests immunomodulatory effects separate from their antibacterial effects [48]. It has been shown that after Francisella infection in mice, there is a delayed response in the induction of host proinflammatory cytokines and recruitment of inflammatory cells to the site of infection, resulting in uncontrolled bacterial replication [49]. G. mellonella, however, does not have a similar immune response following Francisella infection. Since the therapeutic efficacy of Az cannot be observed in G. mellonella, future experiments will be conducted using a mouse model. Our results demonstrate efficacy of Az against multiple different Francisella strains and species. In future work, we will extend the Az studies to murine infections with the fully virulent strain, F. tularensis Schu S4.

\section{Conclusion}

$\mathrm{Az}$ and other macrolide antibiotics may have a secondary benefit to patients with pneumonic tularemia infection since they also have immunomodulatory functions. Az has been used to treat non-infectious respiratory diseases such as diffuse panbronchiolitis (an inflammatory lung disease) and has been shown to reduce cytokine responses in the lungs thereby lessening the acute inflammatory response $[48,50]$, even at sub-antimicrobial doses. $\mathrm{Az}$ is also used in the long-term management of lung transplant patients, including those with bronchiolitis obliterans syndrome, a disease occasionally resulting from the chronic immunological and inflammatory status in some post-transplant lungs [51]. Pulmonary tularemia often exhibits a robust pro-inflammatory response. If $\mathrm{Az}$ proves to be effective against $F$. tularensis in vivo, it may provide a dual therapeutic effect by also mitigating the pro-inflammatory response. Thus, there may be additional non-antimicrobial benefits to the lung as a result of using $\mathrm{Az}$ to treat pulmonary tularemia, which is often complicated by robust pro-inflammatory responses.

The current established treatment protocol for tularemia in children is ciprofloxacin [52]. However, ciprofloxacin has the potential for significant side effects, including liver toxicity, tendonitis and renal failure [40,53,54]. Az 
(trade name: Zithromax) is commonly prescribed to pediatric patients for ear infections and other common gram-negative infections, with very safe outcomes [55]. With the finding that Az concentrates in macrophages and is effective against Francisella species (including LVS) in vitro and in an in vivo infection model, we propose that further studies be done to establish the clinical utility of $\mathrm{Az}$ against tularemia, as an alternative treatment. In case of a deliberate tularemia infection of the population, such as in a biological weapons attack, there may be patients who can not tolerate the standard treatment. Az could be tested either as a stand-alone therapy or in combination with other chemotherapeutic agents. Developing an alternate effective therapy to treat tularemia in patients that do not tolerate ciprofloxacin well, such as pediatric and elderly patients, will lead to safer therapeutic options for physicians.

\section{Methods}

\section{Antibiotics}

The antibiotics investigated in this study were azithromycin (Az) (Biochemika), gentamicin (ATCC), and ciprofloxacin (Biochemika). Az was obtained as $15 \mu \mathrm{g}$ discs (Fluka \# 68601 or Remel \# R33105), and dry powder (Fluka). Az was dissolved in distilled water and ciprofloxacin was dissolved in $0.5 \mathrm{M} \mathrm{HCl}$ to appropriate concentration. Gentamicin was obtained in solution at high concentration $(50 \mathrm{mg} / \mathrm{ml}$, ATCC) and diluted in distilled water.

\section{Bacterial strains}

The following reagents were obtained through the NIH Biodefense and Emerging Infections Research Resources Repository, NIAID, NIH: Francisella philomiragia (ATCC \#25015), F. tularensis holarctica Live Vaccine Strain (LVS) FSC155 (\#NR-646), F. novicida (\#NR-13), and $F$. novicida transposon insertion mutants (Table 7) [56]. Bacteria were grown in trypticase soy broth supplemented with cysteine (TSB-C) for 24 or 48 (for LVS, a slower growing organism) hours at $37^{\circ} \mathrm{C}$ in $5 \% \mathrm{CO}_{2}$ to approximately $10^{10} \mathrm{CFU} / \mathrm{ml}$. F. tularensis tularensis strain NIH B38 (B38) (ATCC 6223; BEI Resources \# NR50, deposited as the type strain for F. tularensis tularensis) was grown on Chocolate II Agar plates (BD Biosciences) at $37^{\circ} \mathrm{C}$ for 72 hours due to their extremely slow growth rate. LPS mutants in $w b t N, w b t E, w b t Q$, and $w b t A$ loci were tested. RND efflux mutants in $d s b B$, $a c r A, a c r B$, tolC, and $f t l C$ were also tested (Table 7). F. tularensis Schu S4 (CDC, Fort Collins, CO) and F. tularensis Schu S4 deletion mutants $\triangle d s b B, \triangle a c r A$, and $\triangle a c r B$ (21) were tested in an approved biosafety level 3 laboratory by trained personnel at the University of Virginia, Charlottesville, VA (Table 7).

\section{Cell culture}

Mouse macrophage cells J774A.1 (ATCC \#TIB-67) and human lung epithelial cells A549 (ATCC \#CCL-185) were obtained from ATCC, Manassas, VA. J774A.1 cells were grown in Dulbecco's Modified Eagle Medium (DMEM) with $10 \%$ fetal bovine serum and passed every 3 days in a 1:3 dilution following manufacturers' instructions. A549 cells were grown in Ham's F-12 with 10\% fetal bovine serum and passed every 3 days in a 1:3 dilution.

\section{Disc inhibition assay}

Kirby-Bauer disc inhibition assay protocol was followed [57]. $100 \mu \mathrm{l}$ of overnight bacterial cultures were spread on Chocolate II agar and Schu S4 strains were spread on Mueller-Hinton agar plate with three discs each containing $15 \mu \mathrm{g} \mathrm{Az}$ placed in a triangle and incubated based on length of time for bacterial growth to be seen on the plate: 24 (for F. novicida, F. philomiragia, and F. tularensis Schu S4), 48 (for F. tularensis LVS), and 72 hours (for $F$. tularensis $\mathrm{NIH} \mathrm{B38)} \mathrm{at} 37^{\circ} \mathrm{C}$ in $5 \% \mathrm{CO}_{2}$. The diameter of the zone of inhibition including the $6 \mathrm{~mm}$ disc was measured (in $\mathrm{mm}$ ) with three independent measurements for each zone $(n=9)$. Inhibition was defined as the area of no bacterial growth around the discs. A reading of $6 \mathrm{~mm}$ indicates no inhibition [57].

\section{Minimal inhibitory concentration (MIC)}

Assays were performed with small modification following published protocols [58]. The MIC for F. novicida, F. philomiragia, $F$. tularensis LVS, related $F$. novicida mutants, F. tularensis Schu S4, and related F. tularensis Schu S4 mutants were determined in TSB-C media by antibiotic dilution in triplicates. The broth was then inoculated with $10^{5} \mathrm{CFU} / \mathrm{ml}$ per strain. Concentration of the antibiotics ranged from $1 \mathrm{mg} / \mathrm{ml}$ to $0.0001 \mu \mathrm{g} / \mathrm{ml}$. The MIC was read at optical density $600 \mathrm{~nm}$ after 24 hours (for F. philomiragia, F. novicida, and $F$. tularensis Schu S4) and after 48 hours (for F. tularensis LVS) and was defined as the lowest concentration of antibiotic with no visible growth.

\section{Data analysis and statistics}

Data were analyzed using the following equation and GraphPad Prism 4 (GraphPad Software Inc., San Diego, CA) [23].

$\mathrm{Y}=$ Bottom $+\left((\right.$ Top-Bottom $) /\left(1+10^{\wedge}\left[\left(\operatorname{LogEC}_{50}-\mathrm{X}\right) *\right.\right.$ Hill Slope $\left.]\right)$.

Y corresponds to bacterial mortality (\% OD, where zero drug $=100 \%)$ at a given antibiotic concentration $(\mu \mathrm{g} / \mathrm{ml})$, with $\mathrm{X}$ being the logarithm of that concentration $(\log \mu \mathrm{g} /$ $\mathrm{ml})$. In the equation, "Top" and "Bottom" refer to the upper and lower boundaries, and were constrained to values $<100 \%$ and $>0 \%$, respectively. $\mathrm{EC}_{50}$ values were determined by fitting the data from the antimicrobial assays to 
Table 7: F. novicida and F. tularensis subsp. tularensis Schu S4 mutants used.

\begin{tabular}{|c|c|c|}
\hline Mutant abbreviation & Mutant name & Gene \\
\hline$w b t N$ & tnfn1_pw060420p04q142 & wbtNFTN_1422 \\
\hline wbtE & tnfn1_pw060328p03q164 & wbtE FTN_1426 \\
\hline wbtQ & tnfn1_pw060419p04q158 & wbtQ FTN_1430 \\
\hline$w b t A$ & tnfn1_pw060419p03q166 & wbtA FTN_1431 \\
\hline tolC & tnfn1_pw060419p03q111 & tolCFTN_1703 \\
\hline tolC* & tnfn1_pw060328p03q137 & tolCFTN_1703 \\
\hline $\mathrm{ft} / \mathrm{C}$ & tnfn1_pw060418p04q166 & Hypothetical protein FTN_0779 \\
\hline$d s b B$ & tnfn1_pw060323p05q173 & $d s b B$ FTN_1608 \\
\hline$a c r A$ & tnfn1_pw060328p06q117 & Membrane fusion protein FTN_1609 \\
\hline$a c r A^{*}$ & tnfn1_pw060419p03q103 & Membrane fusion protein FTN_1609 \\
\hline$a c r B$ & tnfn1_pw060323p02q131 & RND efflux transporter, AcrB/AcrD/AcrF family FTN_1610 \\
\hline$a c r B^{*}$ & tnfn1_pw060418p04q118 & RND efflux transporter, AcrB/AcrD/AcrF family FTN_1610 \\
\hline$\Delta a c r B$ & BJM1032 & Schu S4 $\triangle a c r B[16]$ (FTT0105c) \\
\hline$\triangle a c r A$ & BJM1040 & Schu S4 $\triangle a c r A[16]$ (FTT0106c) \\
\hline
\end{tabular}

a standard sigmoidal dose-response curve (Equation 1) with a Hill slope of 1 . Control samples with no antibiotic are plotted as $10^{\wedge}-4 \mu \mathrm{g} / \mathrm{ml}$ for graphing purposes. Errors were reported based on the standard deviation from the mean of the $\log \mathrm{EC}_{50}$ values. Student's T-test was used to determine whether points were statistically different, using a two tailed test assuming normal distribution.

\section{Cell infection with Francisella strains}

J774A.1 cells and A549 cells were plated (105/well) in a 96-well plate and infected with either F. novicida, F. philomiragia, F. tularensis LVS, or F. novicida transposon mutants at MOI 500 for 2 hour incubation. Extracellular bacteria were removed by washing cell wells twice with DMEM for J774A.1 cells or Ham's F-12 for A549 cells. After Francisella infection and removal of extracellular bacterium, cells were incubated with $50 \mu \mathrm{g} / \mathrm{ml}$ gentamicin for 1 hour to eliminate extracellular bacterium but which does not affect intracellular bacteria. Cells were washed with media twice and incubated with $\mathrm{Az}$ in the media at final concentrations of $0,0.1,5,15,25$, and 35 $\mu \mathrm{g} / \mathrm{ml}$ for 0 or 22 hours at $37^{\circ} \mathrm{C}$.

\section{Quantification of intracellular Francisella bacteria}

After exposure of cells to Francisella and antibiotics, the numbers of intracellular bacteria were determined. At 0 and 22 hours, the samples were washed twice with PBS. Sterile deionized water was used to lyse cells. Aliquots of cells and cell-associated bacteria were serially diluted onto chocolate agar plates, incubated at $37^{\circ} \mathrm{C}$ and $5 \% \mathrm{CO}_{2}$ for 1 or 2 days and the CFU were counted.

\section{Quantification of cellular apoptosis}

After exposure of cells to Francisella and antibiotics, the numbers of cell-associated bacteria were determined, the CytoTox-96 Non-radioactive Cytotoxicity Assay (Promega) was used to quantitatively measure lactate dehy- 
drogenase (LDH) release at 22 hours, following manufacturers' instructions. Absorbance values were recorded at OD $490 \mathrm{~nm}$ by spectrophotometer ( $\mu$ Quant, BioTek). Background noise values were subtracted from sample readings. Determine \% cell death using formula:

$\%$ cytotoxicity $=($ Experimental LDH release - Spontaneous LDH release $) /$ (Maximum LDH release - Spontaneous LDH release)

\section{Galleria mellonella exposure to Francisella strains and treatment with antibiotics}

Galleria mellonella was obtained at the larval stages from Vanderhorst Wholesale (Saint Marys, OH). 10 caterpillars with a weight of 0.30-0.35 g were used for each group. Injection area was cleaned with water and a $10 \mu \mathrm{l} \mathrm{Hamil-}$ ton syringe was used to inject $10 \mu \mathrm{l}$ of $3 \times 10^{6} \mathrm{CFU} / \mathrm{ml}$ of either $F$. novicida or $F$. tularensis LVS into the hemocoel of each caterpillar via the last left proleg and incubated at $37^{\circ} \mathrm{C}$ for 2 hours [25]. Caterpillars were then injected with $10 \mu \mathrm{l}$ of either PBS, $25 \mu \mathrm{g} / \mathrm{ml} \mathrm{Az}$, or $20 \mu \mathrm{g} / \mathrm{ml}$ ciprofloxacin in the last right proleg. Control caterpillars were either not injected or injected with only PBS, azithromycin, or ciprofloxacin. Caterpillar groups were incubated at $37^{\circ} \mathrm{C}$ and scored daily for color change or death.

\section{Authors' contributions}

SA carried out the cell-based assays, the in vitro studies with the mutants and the caterpillar experiments, analyzed the data and contributed to writing the manuscript. $\mathrm{LH}$ conceived the original use of $\mathrm{Az}$ against intracellular Francisella and performed the first in vitro studies of Az's effectiveness, AQ performed the Schu S4 testing, BM designed and coordinated the Schu S4 testing and contributed to the interpretation and conclusions drawn from these studies, MVH conceived of the overall study, designed and coordinated the experiments, and wrote the manuscript. All authors read and approved the final manuscript.

\section{Acknowledgements}

This work was partially supported by funds from the College of Science, George Mason University. Dr Steven D. Nathan, Director of the Advanced Lung Disease Program and the Medical Director of the Lung Transplant Program at Inova Fairfax Hospital, Fairfax, VA contributed helpful discussions about the use of azithromycin in lung transplant patients.

\section{Author Details}

'Department of Molecular and Microbiology, National Center for Biodefense and Infectious Diseases, George Mason University, Manassas, VA, 20120, USA, IInova Fairfax Hospital, Falls Church, VA 22042, USA and 'BDepartments of Medicine \& Microbiology, University of Virginia Health Systems, Charlottesville, VA 22908, USA

Received: 25 November 2009 Accepted: 23 April 2010

Published: 23 April 2010

\section{References}

1. Sjostedt A: Tularemia: history, epidemiology, pathogen physiology, and clinical manifestations. Ann N Y Acad Sci 2007, 1105:1-29.

2. Keim $P$, Johansson A, Wagner DM: Molecular epidemiology, evolution, and ecology of Francisella. Ann N Y Acad Sci 2007, 1105:30-66.

3. Forsman M, Sandstrom G, Jaurin B: Identification of Francisella species and discrimination of type $A$ and type $B$ strains of $F$. tularensis by $16 \mathrm{~S}$ rRNA analysis. Appl Environ Microbiol 1990, 56:949-955.
4. Nano FE, Zhang N, Cowley SC, Klose KE, Cheung KK, Roberts MJ, Ludu JS, Letendre GW, Meierovics Al, Stephens G, Elkins KL: A Francisella tularensis pathogenicity island required for intramacrophage growth. $J$ Bacteriol 2004, 186:6430-6436.

5. Biegeleisen JZ Jr, Moody MD: Sensitivity in vitro of eighteen strains of Pasteurelia tularensis to erythromycin. J Bacterio/ 1960, 79:155-156.

6. Olsufjev NG, Meshcheryakova IS: Infraspecific taxonomy of tularemia agent Francisella tularensis McCoy et Chapin. J Hyg Epidemiol Microbiol Immunol 1982, 26:291-299.

7. Bossi P, Tegnell A, Baka A, Van Loock F, Hendriks J, Werner A, Maidhof $H$, Gouvras G: Bichat guidelines for the clinical management of tularaemia and bioterrorism-related tularaemia. Euro Surveill 2004, 9:E9-10.

8. Hardy DJ, Hensey DM, Beyer JM, Vojtko C, McDonald EJ, Fernandes PB: Comparative in vitro activities of new 14-, 15-, and 16-membered macrolides. Antimicrob Agents Chemother 1988, 32:1710-1719.

9. Vaara M: Outer membrane permeability barrier to azithromycin, clarithromycin, and roxithromycin in gram-negative enteric bacteria. Antimicrob Agents Chemother 1993, 37:354-356.

10. Thomas RM, Titball RW, Oyston PC, Griffin K, Waters E, Hitchen PG, Michell $\mathrm{SL}$, Grice ID, Wilson JC, Prior JL: The immunologically distinct $\mathrm{O}$ antigens from Francisella tularensis subspecies tularensis and Francisella novicida are both virulence determinants and protective antigens. Infect Immun 2007, 75:371-378.

11. Piddock $\sqcup$ : Multidrug-resistance efflux pumps - not just for resistance. Nat Rev Microbiol 2006, 4:629-636

12. Gil H, Platz GJ, Forestal CA, Monfett M, Bakshi CS, Sellati TJ, Furie MB, Benach JL, Thanassi DG: Deletion of TolC orthologs in Francisella tularensis identifies roles in multidrug resistance and virulence. Proc Natl Acad Sci USA 2006, 103:12897-12902.

13. Kobayashi N, Nishino K, Yamaguchi A: Novel macrolide-specific ABCtype efflux transporter in Escherichia coli. J Bacteriol 2001, 183:5639-5644

14. Chollet R, Chevalier J, Bryskier A, Pages JM: The AcrAB-TolC pump is involved in macrolide resistance but not in telithromycin efflux in Enterobacter aerogenes and Escherichia coli. Antimicrob Agents Chemother 2004, 48:3621-3624.

15. Bina $X R$, Lavine $C L$, Miller MA, Bina JE: The AcrAB RND efflux system from the live vaccine strain of Francisella tularensis is a multiple drug efflux system that is required for virulence in mice. FEMS Microbiol Lett 2008, 279:226-233.

16. Qin A, Scott DW, Mann BJ: Francisella tularensis subsp. tularensis Schu S4 disulfide bond formation protein B, but not an RND-type efflux pump, is required for virulence. Infect Immun 2008, 76:3086-3092.

17. Ferwerda A, Moll HA, Hop WC, Kouwenberg JM, Tjon Pian Gi CV, Robben SG, de Groot R: Efficacy, safety and tolerability of 3 day azithromycin versus 10 day co-amoxiclav in the treatment of children with acute lower respiratory tract infections. J Antimicrob Chemother 2001, 47:441-446

18. Amsden GW: Advanced-generation macrolides: tissue-directed antibiotics. Int J Antimicrob Agents 2001, 18(Suppl 1):S11-15.

19. Lai XH, Sjostedt A: Delineation of the molecular mechanisms of Francisella tularensis-induced apoptosis in murine macrophages. Infect Immun 2003, 71:4642-4646.

20. Telepnev M, Golovliov I, Sjostedt A: Francisella tularensis LVS initially activates but subsequently down-regulates intracellular signaling and cytokine secretion in mouse monocytic and human peripheral blood mononuclear cells. Microb Pathog 2005, 38:239-247.

21. Baron GS, Nano FE: MgIA and MgIB are required for the intramacrophage growth of Francisella novicida. Mol Microbiol 1998, 29:247-259.

22. Hall JD, Craven RR, Fuller JR, Pickles RJ, Kawula TH: Francisella tularensis replicates within alveolar type II epithelial cells in vitro and in vivo following inhalation. Infect Immun 2007, 75:1034-1039.

23. Han S, Bishop BM, van Hoek ML: Antimicrobial activity of human betadefensins and induction by Francisella. Biochem Biophys Res Commun 2008, 371:670-674.

24. Craven RR, Hall JD, Fuller JR, Taft-Benz S, Kawula TH: Francisella tularensis invasion of lung epithelial cells. Infect Immun 2008, 76:2833-2842.

25. Aperis G, Fuchs BB, Anderson CA, Warner JE, Calderwood SB, Mylonakis E: Galleria mellonella as a model host to study infection by the Francisella tularensis live vaccine strain. Microbes Infect 2007, 9:729-734. 
26. Seed KD, Dennis JJ: Development of Galleria mellonella as an alternative infection model for the Burkholderia cepacia complex. Infect Immun 2008, 76:1267-1275.

27. Ikaheimo I, Syrjala H, Karhukorpi J, Schildt R, Koskela M: In vitro antibiotic susceptibility of Francisella tularensis isolated from humans and animals. J Antimicrob Chemother 2000, 46:287-290.

28. Urich SK, Petersen JM: In vitro susceptibility of isolates of Francisella tularensis types A and B from North America. Antimicrob Agents Chemother 2008, 52:2276-2278.

29. Mason WL, Eigelsbach HT, Little SF, Bates JH: Treatment of tularemia, including pulmonary tularemia, with gentamicin. Am Rev Respir Dis 1980, 121:39-45

30. Lai XH, Golovliov I, Sjostedt A: Francisella tularensis induces cytopathogenicity and apoptosis in murine macrophages via a mechanism that requires intracellular bacterial multiplication. Infect Immun 2001, 69:4691-4694.

31. Saha S, Savage PB, Bal M: Enhancement of the efficacy of erythromycin in multiple antibiotic-resistant gram-negative bacterial pathogens. J Appl Microbiol 2008, 105:822-828.

32. Marinov KT, Georgieva ED, Ivanov IN, Kantardjiev TV: Characterization and genotyping of strains of Francisella tularensis isolated in Bulgaria. J Med Microbiol 2009, 58:82-85.

33. Pechere JC: Macrolide resistance mechanisms in Gram-positive cocci. Int J Antimicrob Agents 2001, 18(Suppl 1):S25-28.

34. Larsson P, Oyston PC, Chain P, Chu MC, Duffield M, Fuxelius HH, Garcia E, Halltorp G, Johansson D, Isherwood KE, et al:: The complete genome sequence of Francisella tularensis, the causative agent of tularemia. Nat Genet 2005, 37:153-159.

35. Champion MD, Zeng Q, Nix EB, Nano FE, Keim P, Kodira CD, Borowsky M, Young $S$, Koehrsen M, Engels R, et al:: Comparative genomic characterization of Francisella tularensis strains belonging to low and high virulence subspecies. PLoS Pathog 2009, 5:e1000459.

36. Piddock LJ: Clinically relevant chromosomally encoded multidrug resistance efflux pumps in bacteria. Clin Microbiol Rev 2006, 19:382-402.

37. Misra R, Reeves PR: Role of micF in the tolC-mediated regulation of OmpF, a major outer membrane protein of Escherichia coli K-12. J Bacteriol 1987, 169:4722-4730.

38. Biswas S, Raoult D, Rolain JM: A bioinformatic approach to understanding antibiotic resistance in intracellular bacteria through whole genome analysis. Int J Antimicrob Agents 2008, 32:207-220.

39. Kraemer PS, Mitchell A, Pelletier MR, Gallagher LA, Wasnick M, Rohmer L, Brittnacher MJ, Manoil C, Skerett SJ, Salama NR: Genome-wide screen in Francisella novicida for genes required for pulmonary and systemic infection in mice. Infect Immun 2009, 77:232-244.

40. Norcia LJ, Silvia AM, Santoro SL, Retsema J, Letavic MA, Bronk BS, Lundy KM, Yang B, Evans NA, Hayashi SF: In vitro microbiological characterization of a novel azalide, two triamilides and an azalide ketal against bovine and porcine respiratory pathogens. J Antibiot (Tokyo) 2004, 57:280-288.

41. Weiss DS, Brotcke A, Henry T, Margolis JJ, Chan K, Monack DM: In vivo negative selection screen identifies genes required for Francisella virulence. Proc Natl Acad Sci USA 2007, 104:6037-6042.

42. Raynaud C, Meibom KL, Lety MA, Dubail I, Candela T, Frapy E, Charbit A: Role of the wbt locus of Francisella tularensis in lipopolysaccharide Oantigen biogenesis and pathogenicity. Infect Immun 2007, 75:536-541.

43. Cowley SC, Gray CJ, Nano FE: Isolation and characterization of Francisella novicida mutants defective in lipopolysaccharide biosynthesis. FEMS Microbiol Lett 2000, 182:63-67.

44. Shapiro DS, Schwartz DR: Exposure of laboratory workers to Francisella tularensis despite a bioterrorism procedure. J Clin Microbiol 2002, 40:2278-2281

45. Hassoun A, Spera R, Dunkel J: Tularemia and once-daily gentamicin. Antimicrob Agents Chemother 2006, 50:824.

46. Harrell RE Jr, Simmons HF: Pleuropulmonary tularemia: successful treatment with erythromycin. South Med J 1990, 83:1363-1364.

47. Westerman EL, MCDonald J: Tularemia pneumonia mimicking legionnaires' disease: isolation of organism on CYE agar and successful treatment with erythromycin. South Med J 1983, 76:1169-1170.

48. Mizunoe S, Kadota J, Tokimatsu I, Kishi K, Nagai H, Nasu M: Clarithromycin and azithromycin induce apoptosis of activated lymphocytes via down-regulation of Bcl-xL. Int Immunopharmacol 2004, 4:1201-1207.
49. Platz GJ, Bublitz DC, Mena P, Benach JL, Furie MB, Thanassi DG: A tolC Mutant of Francisella tularensis Is Hypercytotoxic Compared to the Wild Type and Elicits Increased Proinflammatory Responses from Host Cells. Infect Immun 78:1022-1031.

50. Hoyt JC, Robbins RA: Macrolide antibiotics and pulmonary inflammation. FEMS Microbiol Lett 2001, 205:1-7.

51. Fietta AM, Meloni F: Lung transplantation: the role of azithromycin in the management of patients with bronchiolitis obliterans syndrome. Curr Med Chem 2008, 15:716-723.

52. Johansson A, Berglund L, Gothefors L, Sjostedt A, Tarnvik A: Ciprofloxacin for treatment of tularemia in children. Pediatr Infect Dis $J 2000$ 19:449-453.

53. Zimpfer A, Propst A, Mikuz G, Vogel W, Terracciano L, Stadlmann S: Ciprofloxacin-induced acute liver injury: case report and review of literature. Virchows Arch 2004, 444:87-89.

54. Dichiara AJ, Atkinson M, Goodman Z, Sherman KE: Ciprofloxacin-induced acute cholestatic liver injury and associated renal failure. Case report and review. Minerva Gastroenterol Dietol 2008, 54:307-315.

55. Akita H, Sato Y, Kusumoto Y, Iwata S, Takeuchi Y, Aoyama T, Yokota T, Sunakawa K: Bacteriological, pharmacokinetic and clinical evaluation of azithromycin in the pediatric field. Jpn J Antibiot 1996, 49:899-916.

56. Gallagher LA, Ramage E, Jacobs MA, Kaul R, Brittnacher M, Manoil C: A comprehensive transposon mutant library of Francisella novicida, a bioweapon surrogate. Proc Natl Acad Sci USA 2007, 104:1009-1014.

57. Bauer AW, Kirby WM, Sherris JC, Turck M: Antibiotic susceptibility testing by a standardized single disk method. Am J Clin Pathol 1966, 45:493-496

58. Baker CN, Hollis DG, Thornsberry C: Antimicrobial susceptibility testing of Francisella tularensis with a modified Mueller-Hinton broth. J Clin Microbiol 1985, 22:212-215.

59. Pos KM: Trinity revealed: Stoichiometric complex assembly of a bacterial multidrug efflux pump. Proc Natl Acad Sci USA 2009, 106:6893-6894.

doi: 10.1186/1471-2180-10-123

Cite this article as: Ahmad et al., Azithromycin effectiveness against intracellular infections of Francisella BMC Microbiology 2010, 10:123

\section{Submit your next manuscript to BioMed Centra and take full advantage of:}

- Convenient online submission

- Thorough peer review

- No space constraints or color figure charges

- Immediate publication on acceptance

- Inclusion in PubMed, CAS, Scopus and Google Scholar

- Research which is freely available for redistribution 